\title{
PENGARUH KUALITAS PELAYANAN TERHADAP KEPUASAN PELANGGAN PADA PERCETAKAN RUBY PRINTING
}

\author{
(STUDI KASUS PELANGGAN DI PERCETAKAN RUBY PRINTING BEKASI)
}

\author{
OCTA NILAM LUKKITA ${ }^{1}$, YENI AGUSTINA ${ }^{2}$ \\ octa.nilam@ibm.ac.id ${ }^{1}$, yeni.agustina@gmail.com ${ }^{2}$ \\ Prodi Manajemen \\ Institut Bisnis Muhammadiyah Bekasi
}

\begin{abstract}
This study aims to investigate: (1) the effect of reliability on customers' satisfaction, (2) the effect of responsiveness on customer satisfaction, (3) the effect of assurance on customer satisfaction, (4) the effect of empathy on customer satisfaction, (5) the effect of tangibles on customer satisfaction, and (60 the effects of reliability, responsiveness, assurance, empathy and tangible on customer satisfaction. This was a quantitative study. The research setting was Ruby Printing Bekasi, the research population comprised customers Ruby Printing. The research sample was selected using Lameshaw, resulting in 96,4 rounded to 100. The data collecting technique was a closed questionnaire with answer alternatives using the Likert Scale. The analysis technique was multiple linear regression analysis using $F$-test and $t$-test.
\end{abstract}

Keywords: Service Quality, Customer Satisfaction

\section{PENDAHULUAN}

Semakin banyaknya persaingan dalam industri jasa percetakan memaksa Ruby Printing untuk mencari strategi yang paling tepat untuk memenangkan persaingan. Salah satu strategi untuk meraih kesuksesan dalam industri jasa percetakan adalah dengan menciptakan kepuasan pelanggan. Berdasarkan survey yang dilakukan peneliti, kualitas pelayanan di Ruby printing kurang optimal. Fasilitas yang disediakan oleh percetakan Ruby Printing kurang memadai yang membuat konsumen merasa tidak nyaman, seperti ruang tunggu yang sempit, sehingga cuaca terasa panas, hubungan karyawan dengan pelanggan yang kurang ramah, kurang promosi serta dan kinerja pelayanan yang menentukan kepuasan pelanggan. Beberapa faktor tersebut dapat menyebabkan kepuasan pelanggan menurun.

Menurut Schanrs dalam Tjiptono (2009:24), pada dasarnya tujuan suatu bisnis adalah untuk menciptakan para pelanggan yang merasa puas. Terciptanya kepuasan pelanggan dapat memberikan beberapa manfaat, di antaranya hubungan antara perusahaan dan pelanggannya menjadi harmonis, memberikan dasar yang baik bagi pembelian ulang dan terciptanya loyalitas pelanggan, dan membentuk suatu rekomendasi dari mulut ke mulut (wordof-mouth) yang menguntungkan bagi perusahaan. Salah satu faktor yang mempengaruhi kepuasan pelanggan di percetakan Ruby Printing yaitu kualitas pelayanan sehingga dapat mempengaruhi kepuasan pelanggan dan akan memberi pengaruh pada peningkatan penjualan di percetakan Ruby Printing. 
Untuk menilai atau mengukur kualitas layanan kita perlu memahami mengenai dimensi kualitas layanan. Banyak penelitian mengenai faktor faktor yang mempengaruhi kualitas layanan. Banyak juga penelitian dilakukan oleh para pakar di bidang manajemen jasa untuk mengetahui secara rinci dimensi kualitas yang mempengaruhi kualitas layanan termasuk menentukan dimensi mana yang menentukan paling menentukan dalam kualitas jasa tertentu. Parasuraman (1988 dalam Jasfar, 2009:51) mengemukakan 5 dimensi kualitas layanan adalah reliability (keandalan), responsiveness (daya tanggap), assurance (jaminan), empathy (empati) dan tangible (bukti fisik).

Penelitian ini dirancang untuk menguji tingkat pelayanan terhadap kepuasan pelanggan dan untuk mengetahui apakah kualitas pelayanan berupa wujud fisik (tangible), kehandalan (reliability), daya tanggap (responsiveness), jaminan (assurance) dan kepedulian (emphaty) berpengaruh pada kepuasan pelanggan.

\section{TINJAUAN PUSTAKA}

\section{Kualitas Pelayanan}

Menurut Wyckof, kualitas pelayanan adalah sebuah tingkat keunggulan yang diharapkan, serta berkaitan dengan hal itu adalah tindakan pengendalian atas tingkat keunggulan tersebut untuk memenuhi harapan konsumen. Wyckof melihat kualitas pelayanan tidak dipandang berdasarkan sudut pandang produsen melainkan dari persepsi orang yang menerima Dimensi Kualitas Pelayanan

Parasuraman (1988 dalam Jassfar, 2009:51) mengemukakan lima dimensi kualitas layanan adalah reliability (keandalan), responsiveness (daya tanggap), assurance (jaminan), empathy (empati) dan tengible (produk-produk jasa).

Tabel 2.1 Dimensi Kualitas

\begin{tabular}{|l|l|}
\hline Reliability & $\begin{array}{l}\text { Kemampuan untuk memberikan layanan yang dijanjikan dengan tepat dan } \\
\text { kemampuan untuk dipercaya terutama memberikan jasa secara tepat waktu. }\end{array}$ \\
\hline Responsiveness & $\begin{array}{l}\text { Kemauan atau keinginan para karyawan untuk membantu memberikan jasa } \\
\text { yang dibutuhkan konsumen. }\end{array}$ \\
\hline Assurance & $\begin{array}{l}\text { Meliputi pengetahuan, kemampuan, ramah, sopan dan sifat dapat dipercaya } \\
\text { dari kontak personal untuk menghilangkan sifat keragu-raguan konsumen dan } \\
\text { merasa terbebas dari bahaya dan risiko. }\end{array}$ \\
\hline Empathy & $\begin{array}{l}\text { Meliputi sikap kontak personal maupun perusahaan untuk memahami } \\
\text { kebutuhan maupun kesulitan konsumen, komunikasi yang baik, perhatian } \\
\text { pribadi, kemudian dalam melakukan komunikasi atau hubungan. }\end{array}$ \\
\hline Tangibles & \begin{tabular}{l} 
Terjadinya fasilitas fisik, perlengkapan dan sarana proses jasa. \\
\hline
\end{tabular}
\end{tabular}




\section{Kepuasan Pelanggan}

$\begin{array}{rrr}\text { Menurut } & \text { Zeithmal dan } & \text { Bitner } \\ \text { (2000) definisi kepuasan adalah } & \text { respon }\end{array}$ atau tanggapan konsumen mengenai pemenuhan kebutuhan. Kepuasan merupakan penilaian mengenai ciri atau keistimewaan produk atau jasa. Atau produk itu sendiri yang menyediakan tingkat kesenangan konsumen berkaitan dengan pemenuhan kebutuhan konsumsi konsumen.

\section{Hubungan Antar Variabel Penelitian}

\section{1) Pengaruh Keandalan (reliability) terhadap Kepuasan Pelanggan}

Keandalan adalah kemampuan memberikan pelayanan yang sesuai dengan kebutuhan pelanggan secara cepat, tepat dan dipercaya. Oleh karena itu, kinerja karyawan Ruby Printing harus sesuai atau bahkan melebihi harapan yang dibayangkan oleh pelanggan tanpa ada kesalahan dan mempunyai sikap yang simpatik dan mampu memenuhi janji dalam memberikan pelayanan yang segera dan memuaskan bagi pelanggan. Keandalan mempunyai pengaruh positif terhadap kepuasan pelanggan. Jika keandalan karyawan kurang dari apa yang diharapkan pelanggan, maka keandalan percetakan dianggap kurang memuaskan. 5) Jika keandalan karyawan sama seperti yang diharapkan pelanggan, maka keandalan percetakan dikategorikan memuaskan.

\section{2) Pengaruh Daya Tanggap \\ (Responsivenes) terhadap Kepuasan Pelanggan}

Daya tanggap adalah respon karyawan dalam membantu pelanggan mengatasi masalah yang sedang dihadapi. Tanggapan adalah suatu kebijakan yang membantu memberikan pelayanan yang cepat dan menyampaikan informasi yang jelas. Daya tanggap berpengaruh positif terhadap kepuasan. Jika daya tanggap karyawan sama seperti apa yang diharapkan pelanggan, maka daya tanggap dikategorikan memuaskan.

\section{3) Pengaruh Jaminan (assurance) terhadap} Kepuasan Pelanggan

Jaminan adalah memberikan pelayanan dengan menyampaikan informasi dan menanamkan rasa percaya kepada pelanggan bahwa transaksi produksi tidak akan mengecewakan kepercayaan pelanggan yang telah diberikan kepada percetakan Ruby Printing. Jika jaminan percetakan sesuai apa yang diharapkan pelanggan, maka jaminan di percetakan Ruby Printing dikategorikan memuaskan.

4) Pengaruh Empati (empathy) terhadap Kepuasan Pelanggan

Empati adalah suatu perhatian secara pribadi yang diberikan karyawan Ruby Printing terhadap pelanggan dan menampung keinginan dan kebutuhan pelanggan guna memperbaiki kinerja percetakan Ruby Printing agar sesuai dengan kebutuhan dan keinginan pelanggan. Empati memiliki hubungan yang positif terhadap kepuasan pelanggan. Jika empati yang dilakukan percetakan sesuai apa yang diharapkan pelanggan maka pelanggan akan merasa puas.

\section{Pengaruh Bukti Fisik (tangible) terhadap Kepuasan Pelanggan}

Bukti langsung adalah pemberian fasilitas, sarana dan prasarana berwujud secara langsung atau nyata seperti gedung, kelengkapan, peralatan, penampilan karyawan dll. Bukti langsung memiliki pengaruh positif terhadap kepuasan pelanggan. Jika bukti langsung percetakan kurang dari apa yang diharapkan pelanggan, maka bukti langsung dari percetakan kurang memuaskan. Jika bukti langsung percetakan sesuai dengan apa yang diharapkan maka bukti langsung percetakan dikategorikan memuaskan. 


\section{Hipotesis Penelitian:}



\section{Metode}

Populasi dari penelitian ini adalah pelanggan pada percetakan Ruby Printing Bekasi.

Jumlah sampel yang diambil dalam penelitian ini menggunakan rumus Lemeshow, hal ini dikarenakan jumlah populasi tidak diketahui atau tidak terhingga. Rumus Lameshow yaitu:

jumlah sampel yang akan diambil adalah:

$$
\begin{aligned}
& \mathrm{n}=\frac{\mathrm{z}^{2} 1-\alpha / 2 \mathrm{P}(1-\mathrm{P})}{\mathrm{d}^{2}} \\
& \mathrm{n}=\frac{1,96^{2} \cdot 0,5(1-0,5)}{0,1^{2}} \\
& \mathrm{n}=\frac{3,8416 \cdot 0,25}{0,01} \\
& \mathrm{n}=96,4=100
\end{aligned}
$$

Keterangan:

$$
\begin{aligned}
& \mathrm{n}=\text { Jumlah sampel } \\
& \mathrm{z}=\text { skor } \mathrm{z} \text { pada kepercayaan } 95 \%=1,96 \\
& \mathrm{p}=\text { maksimal estimasi }=0,5 \\
& \mathrm{~d}=\text { alpha }(0,10) \text { atau sampling error } 10 \%
\end{aligned}
$$

Sehingga jika berdasarkan rumus tersebut maka yang didapatkan adalah $96,4=100$ orang sehingga pada penelitian ini setidaknya penulis harus mengambil data dari sampel sekurangkurangnya sejumlah 100 orang.

\section{TEKNIK PENGUMPULAN DATA}

\section{Uji Normalitas}

Uji normalitas bertujuan untuk menguji apakah dalam model regresi, pola seperti distribusi normal, yaitu distribusi data tersebut tidak variabel pengganggu atau residual memiliki distribusi normal. Jika asumsi ini dilanggar, maka uji statistik menjadi tidak valid atau bias terutama untuk sampel kecil. Data yang baik adalah data yang mempunyai menceng ke kiri atau ke kanan. Jika data menyebar di sekitar garis diagonal, maka model regresi memenuhi asumsi normalitas atau dengan menggunakan angka dengan mendapatkan $\alpha \quad 0,05$ (Imam Ghozali, 2009: 160). Uji normalitas ini menggunakan uji Kolmogorov Smirnov dengan sampel berjumlah 100 dan menggunakan taraf signifikansi 0,05. Data akan dikatakan normal jika signifikansi lebih besar dari 0,05. Sebaliknya, jika data signifikansi lebih 
kecil dari 0,05 maka distribusi data dikatakan dikatakan tidak normal.

\section{Uji Linieritas}

Uji linearitas digunakan untuk mengetahui hubungan variabel bebas dengan variabel terikat bersifat linear atau tidak. Linearitas variabel dilihat dari ANOVA Table hasil uji $\mathrm{F}$ untuk baris Deviation from linearity. Pengujian linearitas dalam penelitian ini menggunakan uji $\mathrm{F}$ pada taraf signifikasi 5\%. Jika nilai sig > 0,05 maka hubungan antar variabel adalah linier. Sebaliknya jika nilai sig signifikansi lebih kecil dari 0,05 maka hubungan antar variabel tidak linier. Apabila data yang digunakan dalam penelitian setelah diuji tidak linier analisis data tidak berlaku, karena prasayarat dalam asumsi data ini harus linier.

\section{Uji Multikolinieritas}

Uji multikolinieritas bertujuan untuk menguji apakah dalam model regresi yang terbentuk ada kolerasi yang tinggi atau sempurna di antara variabel bebas. Gejala multikolinieritas dapat dikoreksi dengan menggunakan metode TOL (Tolerance) dan VIF (Variance Inflation Factor), apabila nilai VIF $<10$ (kurang dari 10) dan nilai tolerance-nya $>0,10$ (lebih dari 10), maka tidak terjadi multikolinieritas.

\section{Uji Heterokedastisitas}

Uji heterokedastisitas bertujuan menguji apakah model regresi terjadi ketidaksamaan variance dari residual satu pengamatan ke pengamatan yang lain. Jika variance dari residual satu pengamatan ke pengamatan yang lain tetap, maka disebut Homoskedastisitas dan jika berbeda disebut Heterokedastisitas. Model regresi yang baik adalah yang Homoskesdastisitas atau tidak terjadi Heterokesdastisitas. Kebanyakan data crossection mengandung situasi heteroskesdastisitas karena data ini menghimpun data yang mewakili berbagai ukuruan (kecil, sedang dan besar) (Ghozali, 2013:139). Ada beberapa cara untuk mendeteksi ada atau tidaknya heteroskesdastisitas, antara lain:

1. Melihat grafik plot antara nilai prediksi variabel terikat (dependen) yaitu ZPRED dengan residual SRESID. Deteksi ada tidaknya heteroskedastisitas dapat dilakukan dengan melihat ada tidaknya pola tertentu pada grafik scatterplot antara SRESID dan ZPRED dimana sumbu $\mathrm{Y}$ adalah $\mathrm{Y}$ yang telah diprediksi dan sumber $\mathrm{X}$ adalah residual ( $\mathrm{Y}$ prediksi - Y sesungguhnya) yang telah distudentized.

\section{Dasar Analisis:}

a). Jika ada pola tertentu, seperti titiktitik yang ada membentuk pola tertentu yang teratur (bergelombang, melebar kemudian 70 menyempit), maka mengindikasikan telah terjadi heteroskedastisitas.

b). Jika tidak ada pola yang jelas, serta titik-titik menyebar di atas dan di bawah angka 0 pada sumbu Y, maka tidak terjadi heteroskedastisitas.

2 Uji Glejser mengusulkan untuk meregresi nilai absolut residual terhadap variabel independen. Hasil probabilitas dikatakan signifikan jika nilai signifikansinya di atas tingkat kepercayaan $5 \%$.

\section{Uji Hipotesis}

Uji hipotesis menggunakan persamaan linier berganda. Analisis linier berganda adalah hubungan secara linier antara dua atau lebih variabel independen dengan variabel dependen. Analisis ini untuk mengetahui arah hubungan antara hubungan variabel independen dengan variabel dependen apakah mempunyai hubungan positif atau hubungan negatif dan untuk memprediksi nilai dari variabel dependen apabila nilai variabel independen mengalami kenaikan atau 
penurunan. Persamaan linier berganda penelitian ini adalah sebagai berikut:

$$
\begin{aligned}
& \mathrm{Y}=\mathrm{b} 1 \mathrm{X} 1+\mathrm{b} 2 \mathrm{X} 2+\mathrm{b} 3 \mathrm{X} 3+\mathrm{b} 4 \mathrm{X} 4+ \\
& \mathrm{b} 5 \mathrm{X} 5+\mathrm{e}
\end{aligned}
$$

Keterangan:

$\mathrm{Y}=$ kepuasan pelanggan

b1 $=$ koefisien regresi keandalan

b2 $=$ koefisien regresi daya tanggap

b3 $=$ koefisien regresi jaminan

b4 $=$ koefisien regresi empati

b5 $=$ koefisien regresi bukti fisik

$\mathrm{X} 1=$ keandalan

$\mathrm{X} 2$ = daya tanggap

$\mathrm{X} 3=$ jaminan

$\mathrm{X} 4$ = empati

X5 = bukti fisik

$\mathrm{e}=$ varians pengganggu

Hipotesis dari persamaan ini digunakan untuk uji $t$ dan uji $F$.

\section{Uji Parsial (Uji t)}

Uji statistik $t$ pada dasarnya menunjukkan seberapa jauh pengaruh satu variabel independen secara individual dalam menerangkan variabel dependen. Hipotesis nol (H0) yang hendak diuji adalah apakah suatu parameter $(\beta 1)$ sama dengan nol atau $\mathrm{H} 0$

: $\beta 1=0$ yang artinya adalah apakah suatu variabel independen bukan merupakan penjelas yang signifikan

terhadap variabel dependen. Hipotesis alternatifnya $(\mathrm{Ha})$, parameter suatu variabel tidak sama dengan atau $\mathrm{Ho}: \beta \mathrm{k}$ $\neq 0$ yang artinya adalah variabel tersebut merupakan penjelas yang signifikan terhadap variabel dependen (Kuncoro, 2001). Pengambilan keputusan dengan tingkat signifikan $(\alpha)=0,05$ ditentukan sebagai berikut.

Dasar pengambilan keputusan ditentukan dengan cara sebagai berikut:

a. Jika Jika tingkat signifikansi t hitung $>0,05$ atau thitung < t tabel, maka

H0 diterima.

b. tingkat signifikansi t hitung $<0,05$ atau $\mathrm{t}$ hitung $>\mathrm{t}$ tabel, maka $\mathrm{H} 0$ ditolak.

\section{Uji Simultan (Uji F)}

Uji $F$ pada dasarnya menunjukkan apakah semua variabel bebas yang dimasukkan dalam model mempunyai pengaruh secara bersama-sama terhadap variabel terikat hipotesis nol (H0) yang hendak diuji adalah apakah semua parameter dalam model sama dengan nol atau $\mathrm{H} 0: \beta_{1}=\beta_{2} \ldots=\beta_{\mathrm{k}}=0$ yang artinya apakah semua variabel independen bukan merupakan penjelas yang signifikan terhadap variabel dependen. Hipotesis alternatifnya $(\mathrm{Ha})$, tidak semua parameter simultan sama dengan 0 atau $\mathrm{H} 0: \beta$ 皮 $\beta$ $2 \ldots . \ldots \beta_{\mathrm{k}}=0$ yang artinya adalah semua variabel independen secara simultan merupakan penjelas yang signifikan terhadap variabel dependen (Kuncoro, 2001)

Kriteria pengujian:

a. Jika tingkat signifikansi $\mathrm{F}>0,05$ atau $\mathrm{F}$ hitung < F tabel, maka H0 diterima.

b. Jika tingkat signifikansi $\mathrm{F}<0,05$ atau $\mathrm{F}$ hitung > F tabel, maka $\mathrm{H} 0$ ditolak.

\section{Uji Validitas}

Nilai rtabel dilihat pada tabel r pada $\alpha 0,05$ $(5 \%)$ dengan degree of freedom $(\mathrm{df})=\mathrm{n}-$ 2. Jumlah data $(\mathrm{n})=100$ maka $\mathrm{df}=98 . \mathrm{r}$ $(0,05 ; 98)$ pada uji dua arah $=0,196$. Pada 5 dimensi kualitas pelayanan dan variabel kepuasan pelanggan, setelah dilakukan pengujian, seluruh item dinyatakan valid. Butir-butir pengukuran yang ditampilkan diatas merupakan butir-butir yang memenuhi kriteria pengujian validitas karena karena Corrected Item - Total Correlation (rhitung) > rtabel 0,196.

\section{Uji Reliabilitas}

Uji reliabilitas dimensi keandalan, daya tanggap, jaminan, empati, bukti fisik dan variabel kepuasan pelanggan didapatkan hasil bahwa nilai Cronbach's alpha $\geq$ 0,600. Setelah dilakukan pengujian, seluruh item dinyatakan reliabel. Butir- 
butir pengukuran yang ditampilkan merupakan butir-butir yang memenuhi kriteria pengujian reliabilitas karena nilai Cronbach's alpha $\geq 0,600$.

\section{Uji Normalitas}

Menurut Imam Ghozali (2001:161). Model regresi dikatakan berdistribusi normal jika data ploting (titik-titik) yang menggambarkan data sesungguhnya mengikuti garis diagonal

\section{Uji heteroskedastisitas}

Uji Glejser diatas diartikan bahwa di dalam regresi tidak terdapat gejala heterokedastisitas menunjukkan bahwa tidak ada satupun variabel independen yang signifikan secara statistik mempengaruhi variabel dependen nilai ABS RES, hal tersebut dikarenakan probabilitas signifikansinya $>0,05$ atau 5\% (Ghozali, 2018:134).

\section{Uji Hipotesis Penelitian} Uji Parsial (Uji t)
Uji $t$ merupakan pengujian untuk menunjukkan pengaruh secara individu variabel bebas yang ada dalam model terhadap variabel terikat. untuk menunjukkan pengaruh secara individu variabel bebas terhadap variabel terikat juga dapat dilihat pada nilai signifikansinya. Pengujian ini dilakukan dengan membandingkan t-hitung dengan $\mathrm{t}$ tabel. Suatu variabel independen dikatakan berpengaruh signifikansi jika t-hitung $>\mathrm{t}-$ tabel dengan tingkat signifikansi $5 \%$. Rumus untuk menentukan t-tabel yaitu sebagai berikut:

$\mathrm{t}$ tabel $=\alpha / 2=0,05 / 2=0,025$

Derajat kebebasan $=\mathrm{n}-\mathrm{k}-1=100-5-1$

Dalam penelitian ini maka diperoleh nilai t-tabel 1,9852. Selain dengan membandingkan nilai thitung dengan ttabel, dapat juga dilihat dari besarnya nilai signifikan. Jika nilai sig<0,05 maka variabel independen secara individu berpengaruh terhadap variabel dependen.

Tabel 4.18 Hasil Uji t

\begin{tabular}{|l|r|r|r|r|r|}
\hline \multirow{2}{*}{ Model } & \multicolumn{2}{|c|}{$\begin{array}{c}\text { Unstandardized } \\
\text { Coefficients }\end{array}$} & \multicolumn{1}{c|}{$\begin{array}{c}\text { Standardized } \\
\text { Coefficients }\end{array}$} & \multicolumn{1}{c|}{ T } \\
\cline { 2 - 4 } & \multicolumn{1}{|c|}{ B } & Std. Error & Beta & & \\
\hline Constant &, 726 & 1,137 & &, 639 &, 525 \\
\hline Reliablility &, 208 &, 128 &, 125 & 1,623 &, 108 \\
\hline Responsivenes &, 329 &, 104 &, 228 & 3,161 &, 002 \\
\hline Assurance &, 317 &, 122 &, 209 & 2,596 &, 011 \\
\hline Empathy &, 246 &, 162 &, 117 & 1,519 &, 132 \\
\hline Tengible &, 458 &, 073 &, 396 & 6,241 &, 000 \\
\hline
\end{tabular}

Sumber: data primer yang diolah SPSS 25.0 
a. Pengaruh Keandalan terhadap Kepuasan Pelanggan

Berdasarkan hasil perhitungan secara parsial pengaruh keandalan terhadap kepuasan anggota diperoleh nilai $\mathrm{t}$ hitung sebesar $1,623<$ nilai ttabel 1,9852 dengan sig. $0,108>0,05$ maka Ho diterima dan Ha ditolak. Berdasarkan kriteria yang telah disebutkan, maka bisa diambil kesimpulan bahwa keandalan tidak berpengaruh signifikan terhadap kepuasan anggota.

b. Pengaruh Daya Tanggap terhadap Kepuasan Pelanggan

Berdasarkan hasil perhitungan secara parsial pengaruh daya tanggap terhadap kepuasan anggota diperoleh nilai $t-$ hitung sebesar 3,161> nilai t-tabel 1,9852 dengan sig. $0,002<0,05$ maka Ho ditolak dan $\mathrm{Ha}$ diterima. Berdasarkan kriteria yang telah disebutkan di atas maka bisa diambil kesimpulan bahwa daya tanggap berpengaruh signifikan terhadap kepuasan anggota.

c. Pengaruh Jaminan terhadap Kepuasan Pelanggan.

Berdasarkan hasil perhitungan secara parsial pengaruh jaminan terhadap kepuasan pelanggan diperoleh nilai thitung sebesar $2,596>$ nilai t-tabel 1,9852 dengan sig. $0,011<0,05$ maka Ho ditolak dan Ha diterima.

Berdasarkan kriteria yang telah disebutkan di atas maka bisa diambil kesimpulan bahwa jaminan berpengaruh signifikan terhadap kepuasan anggota. d. Pengaruh Empati terhadap Kepuasan Pelanggan

Berdasarkan hasil perhitungan secara parsial pengaruh empati terhadap kepuasan anggota diperoleh nilai thitung sebesar $1,519<$ nilai $\mathrm{t}$-tabel 1,9852 dengan sig. 0,132>0,05 maka Ho diterima dan Ha ditolak.

Berdasarkan kriteria yang telah disebutkan di atas maka bisa diambil kesimpulan bahwa empati tidak berpengaruh signifikan terhadap kepuasan pelanggan.

e. Pengaruh Bukti Fisik terhadap Kepuasan Pelanggan

Berdasarkan hasil perhitungan secara parsial pengaruh bukti fisik terhadap kepuasan anggota diperoleh nilai thitung sebesar $6,241>$ nilai t-tabel 1,9852 dengan sig. $0,000<0,05$ maka Ho ditolak dan Ha diterima.

Berdasarkan kriteria yang telah disebutkan diatas maka bisa diambil kesimpulan bahwa bukti fisik berpengaruh signifikan terhadap kepuasan anggota.

\section{Uji Simultan (Uji F)}

Uji simultan digunakan untuk menguji apakah variabel bebas yaitu lima dimensi kualitas pelayanan yang terdiri dari keandalan, daya tanggap, jaminan, empati dan wujud fisik secara bersama-sama berpengaruh terhadap variabel terikat yaitu kepuasan pelanggan. Analisis yang digunakan untuk menguji hipotesis dalam penelitian ini adalah analisis regresi berganda. Tabel berikut adalah rangkuman hasil pengujian hipotesis 
Rangkuman Hasil Regresi Berganda

\begin{tabular}{|c|c|c|c|c|c|c|}
\hline Model & $\begin{array}{c}\text { Koef. } \\
\text { Pediktor }\end{array}$ & t hitung & Sig. & $\mathrm{R}$ & $\mathrm{R}^{2}$ & $\mathrm{~F}$ \\
\hline Konstanta (k) & 0,726 & 0,639 & 0,525 & & & \\
\hline Keandalan & 0,208 & 1,623 & 0,108 & & & \\
\hline Daya tanggap & 0,329 & 3,161 & 0,002 & & & \\
\hline Jaminan & 0,317 & 2,596 & 0,011 & & & \\
\hline Empati & 0,246 & 1,519 & 0,132 & & & \\
\hline Bukti Fisik & 0,458 & 6,241 & 0,000 & & & \\
\hline Summary & & & & 0,883 & 0,779 & \\
\hline Regresion (ANOVA) & & & 0,000 & & & 66,326 \\
\hline
\end{tabular}

Berdasarkan tabel 4.18 ditemukan nilai $F$ pada tabel sebesar 66,326 dengan signifikansi 0,000 . Niai signifikansi yang dihasilkan kurang dari 0,05 dan Fhitung 66,326> Ftabel 2,31maka dapat dikatakan bahwa secara simultan lima dimensi kualitas pelayanan berpengaruh secara signifikan terhadap kepuasan pelanggan Percetakan Ruby Printing dengan demikian hipotesis 6 diterima.

Dari hasil analisis regresi berganda pada tabel 4.17 dapat diketahui persamaan regresi berganda sebagai berikut:

$$
\mathrm{Y}=0,726+0,208 \mathrm{X} 1+0,329 \mathrm{X} 2+
$$$$
0,317 \mathrm{X} 3+0,246 \mathrm{X} 4+0,458 \mathrm{X} 5
$$

Dari persamaan tersebut, maka dapat dijelaskan sebagai berikut:

a Nilai konstanta (a) sebesar 0,726 dapat diartikan jika variabel keandalan (X1), daya tanggap (X2), jaminan (X3), empati (X4) dan bukti fisik (X5) dianggap konstan, maka kepuasan anggota 0,726 . b. Nilai koefisien (b1) pada variabel keandalan adalah 0,208 yang artinya setiap perubahan variabel keandalan $1 \%$ maka akan meningkatkan kepuasan anggota sebesar 0,208\% dengan asumsi variabel bebas yang lain dianggap konstan.

c. Nilai koefisien (b2) pada variabel daya tanggap adalah 0,329 yang artinya setiap perubahan variabel daya tanggap $1 \%$ maka akan meningkatkan kepuasan anggota sebesar $0,329 \%$ dengan asumsi variabel bebas yang lain dianggap konstan.

d. Nilai koefisien (b3) pada variabel daya jaminan adalah 0,317 yang artinya setiap perubahan variabel jaminan $1 \%$ maka akan meningkatkan kepuasan anggota sebesar 0,317\% dengan asumsi variabel bebas yang lain dianggap konstan.

e. Nilai koefisien (b4) pada variabel daya empati adalah 0,246 yang artinya setiap perubahan variabel empati $1 \%$ maka akan 
meningkatkan kepuasan anggota sebesar 0,246 \% dengan asumsi variabel bebas yang lain dianggap konstan.

f Nilai koefisien (b5) pada variabel bukti fisik adalah 0,458 yang artinya setiap perubahan variabel bukti fisik $1 \%$ maka akan meningkatkan kepuasan anggota sebesar $0,458 \%$ dengan asumsi variabel bebas yang lain dianggap konstan. Berdasarkan data yang diperoleh dari hasil analisis yang dilakukan maka dapat ditarik kesimpulan sebagai berikut:

\section{Kesimpulan}

Berdasarkan data yang diperoleh dari hasil analisis yang dilakukan maka dapat ditarik kesimpulan sebagai berikut:

1. Tidak terdapat pengaruh signifikan dari dimensi keandalan terhadap kepuasan pelanggan. Hal tersebut dapat ditunjukkan dengan nilai $\mathrm{t}$ hitung sebesar $1,623<\mathrm{t}$-tabel 1,9852, koefisien regresi (b1) 0,208 dan nilai signifikansi sebesar 0,108 $>0,05$.

2. Terdapat pengaruh signifikan dari dimensi daya tanggap terhadap kepuasan pelanggan. Hal tersebut dapat ditunjukkan dengan nilai $t-$ hitung sebesar 3,161>t-tabel 1,9852, koefisien regresi (b2) 0,329 dan nilai signifikansi sebesar 0,002 $<0,05$.

3. Terdapat pengaruh signifikan dari dimensi jaminan terhadap kepuasan pelanggan. Hal tersebut dapat ditunjukkan dengan nilai t-hitung sebesar 2,596>t-tabel 1,9852, koefisien regresi (b3) 0,317 dan nilai signifikansi sebesar $0,011<$ 0,05 .

4. Tidak terdapat pengaruh signifikan dari dimensi empati terhadap kepuasan pelanggan. Hal tersebut dapat ditunjukkan dengan nilai $\mathrm{t}$ hitung sebesar $1,519<\mathrm{t}$-tabel 1,9852, koefisien regresi (b4) 0,246 dan nilai signifikansi sebesar 0,132 $>0,05$.

5. Terdapat pengaruh signifikan dari dimensi bukti fisik terhadap kepuasan pelanggan. Hal tersebut dapat ditunjukkan dengan nilai $t-$ hitung sebesar 6,241>t-tabel 1,9852, koefisien regresi (b5) 0,458 dan nilai signifikansi sebesar 0,000 $<0,05$.

6. Terdapat pengaruh signifikan status lima dimensi kualitas pelayanan menurut Parasuraman et al., yaitu keandalan, daya anggap, jaminan, empati, dan bukti fisik terhadap kepuasan pelanggan Percetakan Ruby Printing. Hal ini ditunjukkan dengan nilai $\mathrm{F}$ hitung sebesar 66,326 dengan nilai signifikansi $0,000<0,05$. Nilai koefisien determinasi $\left(\mathrm{R}^{2}\right)$ sebesar 0,779 atau $77,9 \%$. Nilai $\mathrm{R}^{2}$ tersebut menunjukkan 77,9 \% dari kepuasan pelanggan dapat dijelaskan oleh variabel keandalan, daya tanggap, jaminan, empati, daya tanggap sedangkan sisanya sebesar $22,1 \%$ dijelaskan oleh variabel lain yang tidak diteliti dalam penelitian ini.

\section{Saran}

Berdasarkan kesimpulan di atas maka peneliti memberikan saran sebagai berikut:

1. Percetakan diharapkan untuk memperhatikan kualitas pelayanan yang ada sekarang, bahkan lebih ditingkatkan lagi untuk memperoleh kepuasan yang lebih bagi para pelanggannya.

2. Karyawan sebaiknya mendapatkan pengarahan yang baik agar mereka memiliki keahlian (keandalan) yang baik 
saat melayani pelanggan, karena karyawan yang memiliki keahlian yang baik diharapkan dapat melayani pelanggan dengan baik dan memuaskan.

3. Agar Ruby Printing menambah karyawan dalam hal desain. Karena sejauh penelitian, beberapa pelanggan mengeluh karena terjadi keterlambatan jadwal cetak. Dalam hal ini faktor yang menyebabkan keterlambatan tersebut adalah operator desain yang hanya dikendalikan oleh satu karyawan saja.

4. Meningkatkan kualitas pelayanan dimensi bukti fisik yaitu meningkatkan daya tarik fasilitas percetakan dan fasilitas yang mendukung kinerja usaha karena terbukti kualitas pelayanan yaitu dimensi bukti fisik berpengaruh terhadap kepuasan pelanggan. 


\section{DAFTAR PUSTAKA}

Arikunto, Suharsimi. 2006.

Prosedur Penelitian suatu Pendekatan Praktik. Jakarta: Rineka Cipta.

Augusty, Ferdinand. 2006. Metode Penelitian Manajemen. Semarang: Badan Penerbit Universitas Diponegoro.

Djarwanto. 1996. Mengenal Beberapa Uji Statistik dalam Penelitian. Yogyakarta: Liberty.

Fandy, Tjiptono. 2016. Service, Quality \& Satisfaction. Yogyakarta. Andi.

Ghozali, Imam. 2009. Aplikasi Analisis Multivariate Dengan Program SPSS, Edisi Keempat. Semarang: Universitas Diponegoro.

J., Supranto. 2006. Pengukuran Tingkat Kepuasan Pelanggan: Untuk Menaikkan Pangsa Pasar. Jakarta: Rineka Cipta.

Kotler, $\quad$ Philip. 1998.

Manajemen Pemasaran: Analisa, Perencanaan, Implementasi, dan Kontrol. Jakarta: PT Prenhallindo.

Laksana, Fajar. 2008. Manajemen Pemasaran. Yogyakarta: Graha Ilmu.

Moenir. 2002. Manajemen Pelayanan Umum Indonesia. Jakarta: Bumi Aksara.

Muhtosim, Arief. 2007. Pemasaran Jasa dan Kualitas Pelayanan. Malang: Bayumedia Publishing.

Nazir. 2011. Metode Penelitian. Bogor: Ghalia Indonesia

Purwanti. 1999. Pelayanan Dalam Jasa. Bandung: Angkasa.

Sugiyono. 2003. Statiska Untuk Penelitian. Bandung: Alfabeta.

Swasta, Basu. 2008. Manajemen Pemasaran Modern. Yogyakarta: Liberty.

Tjiptono, Fandy, \& Greegorius Chandra. 2007. Strategi Pemasaran, Edisi Kedua. Yogyakarta: Penerbit Andi.

Unitomo, Meithiana Indasari. 2019.Pemasaran dan Kepuasan Pelanggan.Surabaya:Unit omo Pres

Zeithaml, V.A., M.J. Bitner. 1996. Service Marketing International Editions. New York: Mc Graw Hill. 
Zulian, Yamit. 2001. Manajemen

Produksi Dan Operasi.

Yogyakarta: Ekonisia.

Ahiyoso, Srikandi Kumadji, dan Anriani

Kusumawati. 2017: Pengaruh

Kualitas Layanan

Terhadap Citra Perusahaan dan

Loyalitas Pelanggan (survey pada

pelanggan digital

Printing Surabaya), Jurnal

Administrasi No.4.
Candy, 2016. Kualitas Pelayanan Jasa Percetakan Terhadap Kepuasan Konsumen Pada

PT. Tri Jaya Mandiri, Bisma, Vol 1, No. 8.

Dewa Made Wisnu Anggrabata, dan Gede Bayu Rahanata. 2015:

Pengaruh Kualitas

PelayananTerhadap Kepuasan

Nasabah pada PT BPR Balidana

Niaga Denpasar.

Darmawati.2016: Pengaruh Kualitas

Pelayanan Terhadap Loyalitas

Pelanggan Dalam Memakai Jasa

Percetakan CV. Rahmat Nur di

Semarang, Ejournal Ilmu

Administrasi Bisnis.

Dwi Mulyono Nugroho. 2015: Pengaruh

Kualitas Pelayanan, Kualitas Produk

Layanan dan Harga Produk Layanan

Terhadap Kepuasan Pelanggan dan

Dampaknya Pada Loyalitas

Pelanggan Prabayar Telkomsel.

Erwina Safitri, Mintarti Rahayu, Nur Khusniyah Indrawati. 2016: Pengaruh Kualitas Pelayanan dan Citra

Perusahaan Terhadap Kepuasan

Pelanggan dan Loyalitas Pelanggan

Service Center.

Irwandi Sukartaadmadja, 2014: Pengaruh Kualitas Jasa Pelayanan dan Kualits Jasa Cetak Terhadap Kepuasan Pelanggan (Pada Percetakan IPB). 